\title{
Diagnosis and preoperative predictive value of serum HE4 concentrations for optimal debulking in epithelial ovarian cancer
}

\author{
ZHIJUN YANG ${ }^{*}$, ZHAOQIN LUO*, BINGBING ZHAO, WEI ZHANG, JIEQING ZHANG, ZHUANG LI and LI LI \\ Department of Gynecologic Oncology, The Affiliated Tumor Hospital of Guangxi Medical University, \\ Nanning, Guangxi 530021, P.R. China
}

Received November 10, 2012; Accepted February 12, 2013

DOI: $10.3892 / 01.2013 .1339$

\begin{abstract}
The aim of this study was to evaluate serum human epididymis protein 4 (HE4) concentrations for the diagnosis and preoperative prediction of optimal debulking in epithelial ovarian cancer. The concentrations of serum HE4 and CA125 in 180 epithelial ovarian cancer patients, 40 benign ovarian tumor patients and 40 healthy female subjects were determined using enzyme-linked immunosorbent assays (ELISAs). The value of determining the serum HE4 concentrations for the diagnosis and preoperative prediction of optimal debulking in epithelial ovarian cancer was also analyzed. The concentration of serum HE4 was $355.2 \pm 221.29 \mathrm{pmol} / 1$ in ovarian cancer, $43.86 \pm 20.87 \mathrm{pmol} / 1$ in benign ovarian tumors and $30.22 \pm 9.64 \mathrm{pmol} / 1$ in healthy individuals, respectively. The serum HE4 levels of patients with ovarian cancer were significantly higher compared with those in the other two groups $(\mathrm{P}<0.01)$, although there were no statistically significant differences $(\mathrm{P}>0.05)$ between the benign ovarian tumors and healthy individuals. The maximum diagnostic value was identified at an HE4 serum concentration of $67.52 \mathrm{pmol} / \mathrm{l}$ and the sensitivity and specificity were 84 and $96 \%$, respectively. The area under the ROC curve was 0.944 (95\% CI, 0.912-0.976; $\mathrm{P}<0.001$ ) and the $\kappa$ value of the diagnosis of epithelial ovarian cancer according to $\mathrm{HE} 4$ was $0.814(\mathrm{P}=0.000)$. The demarcation criterion was $600 \mathrm{pmol} / \mathrm{l}$, where a value $>600 \mathrm{~mol} / \mathrm{l}$ indicates a lower possibility of optimal debulking. HE4 predicted that the sensitivity of the incomplete cytoreductive surgery was $77 \%$ and specificity was $32 \%$. The concentration of serum HE4 is a useful marker for diagnosis and preoperative prediction for the ideal tumor cytoreductive surgery in epithelial ovarian cancer.
\end{abstract}

Correspondence to: Professor Li Li, Department of Gynecologic Oncology, The Affiliated Tumor Hospital of Guangxi Medical University, 22 Shuangyong Road, Nanning, Guangxi 530021, P.R. China

E-mail: lili@gxmu.edu.cn

*Contributed equally

Key words: ovarian neoplasm, HE4, CA125, diagnosis, debulking

\section{Introduction}

Ovarian cancer is the most lethal malignancy among females and the prognosis is poor since ovarian cancer is often at an advanced stage when it is detected (1-2). Early diagnosis of ovarian cancer is likely to improved the cure rate significantly. At present, the sensitivity and specificity of the clinically used markers of ovarian cancer are low for early diagnosis, so a number of studies have attempted to identify a more effective diagnostic marker (3). Human epididymis protein 4 (human epididymis gene product 4 ; HE4) is a marker of ovarian tumors which has significant potential for diagnosis (4). HE4 is a secreted protein coded by the gene WFDC2 and belongs to the lactic acid protein domain family (5-6). It has been demonstrated that HE4 mRNA is highly expressed in ovarian cancer tissue and not expressed in benign ovarian tissue (7). Moore et al (8) observed that HE4 was a useful single marker for differentiating between benign ovarian tumor and ovarian cancer patients. Köbel et al (9) analyzed the expression of a number of ovarian cancer markers in various pathological types of malignant ovarian tumors and observed high expression of HE4 in epithelial ovarian cancer. Since epithelial ovarian cancer accounts for $85-90 \%$ of ovarian cancer among the various pathological types, it is important to study the diagnostic value of HE4 for epithelial ovarian cancer. Cytoreductive surgery combined with platinum-based chemotherapy is the standard treatment for patients with ovarian cancer (10). Accurate preoperative assessments of the degree of malignancy and extent of metastasis are critical for optimal debulking, which is the best available approach for treating ovarian cancer at present (11). Previously, no tumor marker has been established to predict whether optimal debulking is likely to be achieved preoperatively. The aim of the present study was to appraise the diagnostic and preoperative predictive value of serum HE4 concentrations for optimal debulking in ovarian cancer .

\section{Patients and methods}

Source of specimens and clinical data. Serum specimens were obtained from ovarian neoplasm patients and diagnosed pathologically at the Department of Gynecologic Oncology of 
the Affiliated Tumor Hospital of Guangxi Medical University (Nanning, China). There were 180 malignant ovarian epithelial carcinoma patients, including 93 with ovarian serous adenocarcinoma, 38 with mucinous adenocarcinoma, 18 with endometrial adenocarcinoma, 14 with clear cell carcinoma and 17 with undifferentiated carcinoma. The median age was 37.6 years (range, 13-71 years). The surgical-pathological staging according the to FIGO (2004) staging criteria was 57 cases of stages I-II and 123 cases of stages III-IV. There were also 40 patients with benign ovarian tumors, including 13 with ovarian serous adenoma, 4 with benign ovarian teratoma, 10 with ovarian cysts and 13 with other types. The median age of the benign ovarian tumor patients was 43.8 years (range, 14-62 years). Additionally, 40 healthy female subjects were identified by physical examination, with a median age of 42 years (range, 33-50 years). The study was approved by the Ethics Committee of Guangxi Medical University. All patients received an explanation of the aims of the study, provided written informed consent and understood that they were able to withdraw from the study at any time without influencing their oncological or general medical treatment.

\section{Methods}

Sample collection. Venous blood $(3 \mathrm{ml})$ was obtained from each patient and placed in test tubes without anticoagulants. The blood samples were allowed to stand for $1 \mathrm{~h}$ at room temperature after specimen collection and the supernatant was collected after centrifuging at $3000 \mathrm{rpm}$. The samples were stored in a $-80^{\circ} \mathrm{C}$ freezer until tested.

Determination of serum HE4. The concentrations of serum HE4 were determined using the double antibody sandwich enzyme-linked immunosorbent assay (ELISA) method. ELISA kits for serum HE4 detection were purchased from Fujirebio Diagnostics AB (Gothenburg, Sweden) and used according to manufacturer's instructions.

Determination of serum CA125. Serum CA125 was detected using the electrochemiluminescent immunoassay (ECLIA) method. The ECLIA kit was provided by Roche Diagnostics (Mannheim, Germany) and the instrument used was a Roche El70 electrochemiluminescent analyzer which was used according to the manufacturer's instructions. Serum CA125>35 U/ml was considered positive and serum CA125 $\leq 35 \mathrm{U} / \mathrm{ml}$ was considered negative.

Statistical analysis. Data were processed with SPSS 17.0 statistical software and the mean \pm standard deviation was used to denote the measured data. The $\chi^{2}$ test was used to evaluate the enumeration data (the frequency of the positive or negative specimens). One-way analysis of variance was used to compare the concentrations of serum samples and the least significant difference two-sample t-test was used to compare pairwise mean values between groups. The specificity and sensitivity of the diagnosis of ovarian cancer using various HE4 concentrations were calculated using ROC curves and the concentration of HE4 with the greatest diagnostic value was selected as the best cut-off point. Diagnosis consistency was used to calculate $\kappa$ values. The life table method was used to calculate survival rates and survival was compared with Kaplan-Meier survival curves and the log-rank test.

\section{Results}

Comparative analysis of the serum HE4 levels of each group. The concentration of serum HE4 was $355.2 \pm 221.29 \mathrm{pmol} / 1$ in ovarian cancer patients, $43.86 \pm 20.87 \mathrm{pmol} / \mathrm{l}$ in benign ovarian tumors and $30.22 \pm 9.64 \mathrm{pmol} / 1$ in healthy individuals. The difference between the HE4 serum levels of ovarian cancer patients and the other two groups was statistically significant $(\mathrm{P}=0.000)$ and the serum HE4 levels of ovarian cancer patients were significantly higher. The difference between the HE4 serum levels of the benign ovarian tumor lesion and healthy groups was not statistically significant $(\mathrm{P}>0.05)$. The results are shown in Table I.

Analysis of the associations between serum HE4 levels, pathological types and clinical stages of ovarian cancer. The levels of serum HE4 were highest in the serous adenocarcinoma and clear cell carcinoma groups and the difference was statistically significant $(\mathrm{P}=0.019)$ compared with the other types of ovarian cancer. No statistically significant difference was observed between the mucinous adenocarcinoma, endometrial adenocarcinoma and undifferentiated carcinoma groups $(\mathrm{P}>0.05)$. In the comparison of the HE4 content between ovarian cancer stages I-II and III-IV, the difference was statistically significant $(\mathrm{P}=0.001)$. The results are shown in Table II.

\section{Diagnostic value of serum HE4 for ovarian cancer}

ROC curve analysis. An ROC curve was created which showed that the area under the curve was 0.984 (95\% CI, $0.970-0.998, \mathrm{P}<0.001)$ and the $\kappa$ value was $0.814(\mathrm{P}=0.000)$. The maximum diagnostic value occurred when the cut-off for the diagnosis of serum HE4 for ovarian cancer was $65.52 \mathrm{pmol} / \mathrm{l}$. The specificity and sensitivity were $96.2 \%$ and $83.8 \% \%$, respectively, and the positive predictive and negative predictive values were 95.7 and $85.6 \%$, respectively. The results are shown in Fig. 1A.

Comparative analysis of diagnostic value between serum HE4 and CA125 for ovarian cancer. The specificity, sensitivity, positive predictive value and negative predictive value were all higher for HE4 diagnosis of ovarian cancer compared with CA125. The difference between the sensitivities was statistically significant $(\mathrm{P}=0.004)$. The difference in specificities was also statistically significant $(\mathrm{P}=0.003)$. The diagnostic performance of serum HE4 is superior to that of CA125, particularly for stage I-II patients. The difference between the sensitivities of the HE4 and CA125 of stage I-II patient groups was statistically significant $(\mathrm{P}=0.046)$. The results are shown in Table III.

Value of the combination of serum HE4 and CA125 in the diagnosis of ovarian cancer. Fig. 1B shows the ROC curves of serum HE4 and CA125 used alone or combination in the diagnosis of ovarian cancer. Table IV shows a comparison of the areas under the ROC curves. The diagnostic performance was compared between serum HE4, CA125 and HE4 + CA125, if HE4 and CA125 were positive. The specificity of HE4 + CA125 was significantly higher than HE4 or CA125 alone, while the sensitivity was lower compared with HE4 alone, but higher compared with CA125 alone. Table V shows the comparisons of sensitivity, specificity, positive predictive value, negative 
Table I. Comparative analysis of the serum HE4 levels of each group (mean \pm standard deviation).

\begin{tabular}{lccr}
\hline Group & No. of cases & Content of HE4 (pmol/l) & P-value \\
\hline Ovarian cancer & 180 & $355.2 \pm 221.29$ & $0.000^{\mathrm{a}}$ \\
Benign tumor & 40 & $43.86 \pm 20.87$ & $0.002^{\mathrm{b}}$ \\
Healthy control & 40 & $30.22 \pm 9.64$ & $0.453^{\mathrm{c}}$
\end{tabular}

${ }^{\mathrm{a} C}$ Comparison of ovarian cancer with healthy control; ${ }^{\mathrm{b}}$ comparison of ovarian cancer with benign tumor; ${ }^{\mathrm{c}}$ comparison of benign tumor with healthy control. HE4, human epididymis protein 4.

Table II. Associations between serum HE4 levels, pathological types and clinical stages of ovarian cancer.

\begin{tabular}{lcc}
\hline Clinicopathological factors & No. of cases & Content of HE4 (pmol/l) \\
\hline Clinical stage & 57 & $226.43 \pm 196.87$ \\
I-II & 123 & $366.13 \pm 192.16$ \\
III-IV & & $448.11 \pm 159.59$ \\
Pathological type & 93 & $299.90 \pm 206.27$ \\
Serous adenocarcinoma & 38 & $309.90 \pm 206.27$ \\
Mucinous adenocarcinoma & 18 & $418.11 \pm 159.77$ \\
Endometrial adenocarcinoma & 14 & \\
Clear cell carcinoma & &
\end{tabular}

HE4, human epididymis protein 4.

Table III. Comparative analysis of diagnostic value of serum HE4 and CA125.

\begin{tabular}{|c|c|c|c|c|c|c|c|c|}
\hline \multirow[b]{2}{*}{ Group } & \multicolumn{4}{|c|}{ HE4 } & \multicolumn{4}{|c|}{ CA125 } \\
\hline & $\begin{array}{c}\text { Sensitivity } \\
(\%)\end{array}$ & $\begin{array}{c}\text { Specificity } \\
(\%)\end{array}$ & $\begin{array}{l}\text { Positive } \\
\text { predictive } \\
\text { value }(\%)\end{array}$ & $\begin{array}{l}\text { Negative } \\
\text { predictive } \\
\text { value }(\%)\end{array}$ & $\begin{array}{c}\text { Sensitivity } \\
(\%)\end{array}$ & $\begin{array}{c}\text { Specificity } \\
(\%)\end{array}$ & $\begin{array}{l}\text { Positive } \\
\text { predictive } \\
\text { value (\%) }\end{array}$ & $\begin{array}{l}\text { Negative } \\
\text { predictive } \\
\text { value }(\%)\end{array}$ \\
\hline Ovarian cancer & 83.8 & 96.2 & 95.7 & 85.6 & 62.5 & 80.0 & 75.8 & 68.1 \\
\hline Stage I-II & 70.4 & 96.2 & 86.4 & 90.6 & 44.4 & 80.0 & 60.0 & 68.1 \\
\hline
\end{tabular}

HE4, human epididymis protein 4.
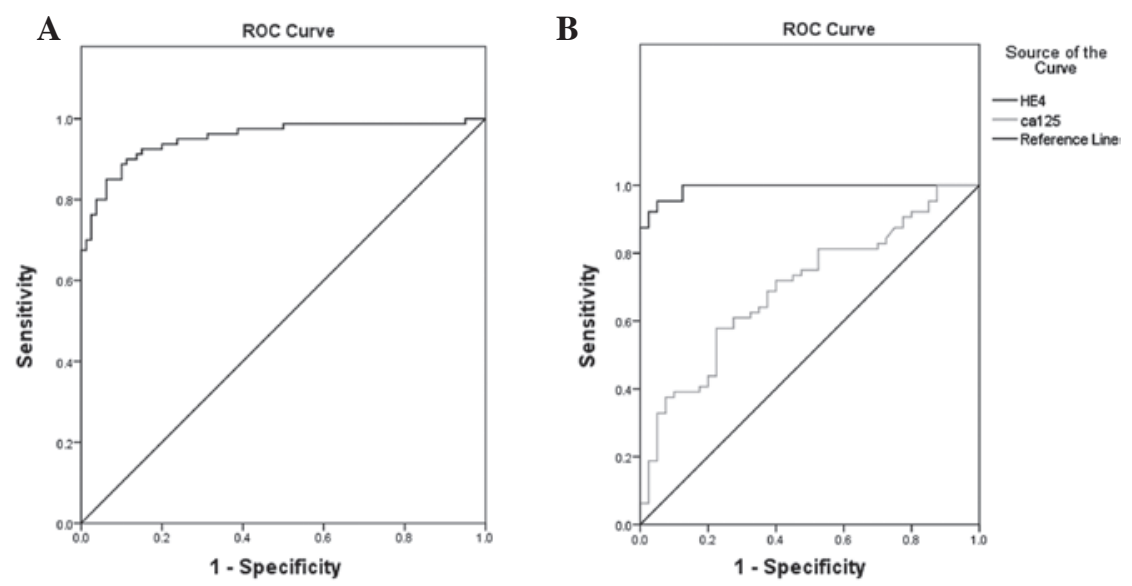

Figure 1. ROC curves of the diagnosis of (A) serum HE4 and (B) HE4 and CA125 for ovarian cancer. HE4, human epididymis protein 4. 
Table IV. Comparison of the area under the ROC curves of serum HE4 and CA125.

\begin{tabular}{lcccc}
\hline Detected marker & Area & Standard error & P-value & 95\% confidence interval \\
\hline HE4 & 0.988 & 0.007 & 0.000 & $0.971-1.000$ \\
CA125 & 0.715 & 0.048 & 0.000 & $0.622-0.809$ \\
\hline
\end{tabular}

HE4, human epididymis protein 4.

Table V. Comparison of the diagnostic performance of serum HE4, CA125 and HE4 + CA125.

\begin{tabular}{lcccccc}
\hline Marker & $\begin{array}{c}\text { Sensitivity } \\
(\%)\end{array}$ & $\begin{array}{c}\text { Specificity } \\
(\%)\end{array}$ & $\begin{array}{c}\text { Positive predictive } \\
\text { value }(\%)\end{array}$ & $\begin{array}{c}\text { Negative predictive } \\
\text { value }(\%)\end{array}$ & $\begin{array}{c}\text { Positive likelihood } \\
\text { ratio }\end{array}$ & $\begin{array}{c}\text { Negative likelihood } \\
\text { ratio }\end{array}$ \\
\hline HE4 & 83.8 & 96.2 & 95.7 & 85.6 & 22.3 & 0.17 \\
CA125 & 62.5 & 80.0 & 75.8 & 68.1 & 3.13 & 0.47 \\
HE4 + CA125 & 65.0 & 98.7 & 98.1 & 73.8 & 52.0 & 0.35 \\
\hline
\end{tabular}

HE4, human epididymis protein 4.

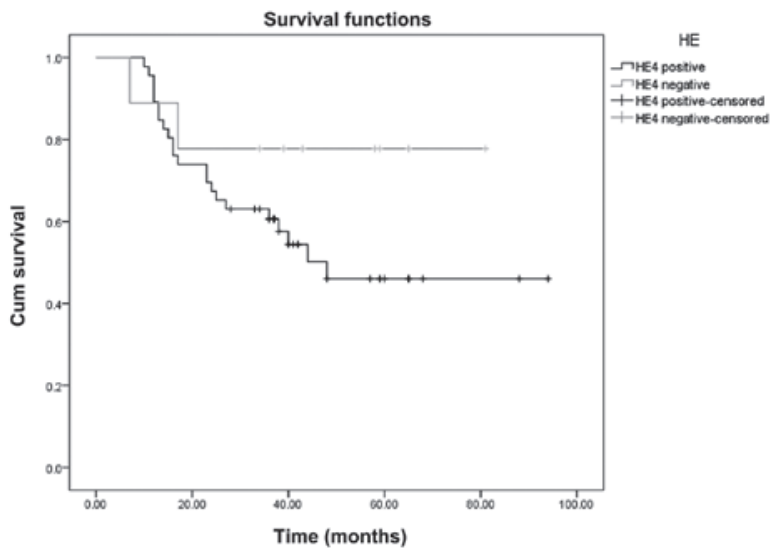

Figure 2. Kaplan-Meier survival curve of serum HE4-positive and negative ovarian cancer patients. HE4, human epididymis protein 4.

predictive value, positive likelihood ratio and negative likelihood ratio.

Association of serum HE4 levels with the prognosis of ovarian cancer patients. All ovarian cancer patients were followed up until December 2011. The one-, two-, three- and four-year cumulative survival rates were $90,62,36$ and $26 \%$, respectively, and the median survival time was 28 months.

Kaplan-Meier survival curve analysis. The Youden index of the ROC curve (Fig. 1A) is at the maximum, the concentration of the serum HE4 is $148.8 \mathrm{pmol} / \mathrm{l}$. With $148.8 \mathrm{pmol} / \mathrm{l}$ as a positive threshold value, the Kaplan-Meier survival curves of serum HE4-positive and negative patients were compared. The log-rank test showed that the curves were significantly different $(\mathrm{P}=0.036)$. The results are shown in Fig. 2.

Cox model analysis of serum HE4 as an independent factor affecting the prognosis of ovarian cancer patients. The Cox proportional hazards regression model was analyzed in accor- dance with the following factors: serum HE4 >67.52 pmol/1, age, pathological type, clinical stage (I-II and III-IV), retroperitoneal lymph node metastasis, omentum metastasis, distant organ transfer and of postoperative residual focal factors. The results showed that the independent factors affecting the prognoses of ovarian cancer patients were the clinical stage, distant organ metastasis and postoperative residual tumors $>2 \mathrm{~cm}$. However, HE4, age, pathological type, retroperitoneal lymph node metastasis and omentum majus metastasis were not independent factors. The results are shown in Table VI.

Association between the serum concentration of HE4 and CA125 and the possibility of optimal debulking in epithelial ovarian cancer. Debulking was performed in all patients. The results of debulking were compared with the preoperative serum concentrations of HE4 and CA125. With $500 \mathrm{U} / \mathrm{ml}$ as the demarcation criterion (CA125), the larger the numbers were, the lower the possibility of optimal cytoreduction surgery. CA125 predicted incomplete cytoreductive surgery with 72 and $30 \%$ sensitivity and specificity, respectively (Fig. 3A). The demarcation criterion of HE4 was $600 \mathrm{pmol} / 1$, where a value $>600 \mathrm{pmol} / 1$ indicates a lower possibility of the optimal cytoreduction surgery. HE4 predicted incomplete cytoreductive surgery with a sensitivity and specificity of 77 and $32 \%$, respectively (Fig. 3B).

\section{Discussion}

The present study showed that the concentration of HE4 in ovarian cancer patients was significantly higher than that in benign ovarian tumor and normal control patients $(\mathrm{P}<0.01)$, and no statistically significant differences were observed $(\mathrm{P}>0.05)$ between the benign ovarian tumor lesion and normal control groups. The mechanism of HE4 overexpression in ovarian cancer is not clear. However, the results of Berry et al (12) showed that the chromosomal region where $\mathrm{HE} 4$ is located is frequently amplified in breast cancer and 
Table VI. Status of each factor in affecting the prognoses of ovarian cancer patients by Cox proportional hazards model analysis.

\begin{tabular}{|c|c|c|c|c|c|c|c|}
\hline \multirow[b]{2}{*}{ Factor } & \multirow{2}{*}{$\begin{array}{l}\text { Regression } \\
\text { coefficient }\end{array}$} & \multirow{2}{*}{$\begin{array}{c}\text { Standard } \\
\text { error }\end{array}$} & \multirow[b]{2}{*}{ Statistic } & \multirow{2}{*}{$\begin{array}{l}\text { Degree of } \\
\text { freedom }\end{array}$} & \multirow[b]{2}{*}{ P-value } & \multicolumn{2}{|c|}{$95.0 \%$ confidence interval } \\
\hline & & & & & & Lower limit & Upper limit \\
\hline HE4 & 1.090 & 1.608 & 0.460 & 1 & 0.498 & 0.127 & 69.598 \\
\hline Age & 0.028 & 0.019 & 2.146 & 1 & 0.143 & 0.991 & 1.067 \\
\hline Pathological type & -0.138 & 1.476 & 0.009 & 1 & 0.926 & 0.048 & 15.726 \\
\hline Stage & 3.526 & 1.415 & 6.211 & 1 & 0.013 & 2.123 & 543.591 \\
\hline Lymph node & -0.328 & 0.544 & 0.365 & 1 & 0.546 & 0.248 & 2.090 \\
\hline Omentum majus & 0.965 & 0.713 & 1.830 & 1 & 0.176 & 0.648 & 10.623 \\
\hline Ascites & 0.491 & 0.544 & 0.815 & 1 & 0.367 & 0.562 & 4.748 \\
\hline Metastasis & -1.375 & 0.651 & 4.463 & 1 & 0.035 & 0.071 & 0.905 \\
\hline Postoperative residual foci & -2.758 & 1.064 & 6.721 & 1 & 0.010 & 0.008 & 0.510 \\
\hline
\end{tabular}

HE4, human epididymis protein 4.

A

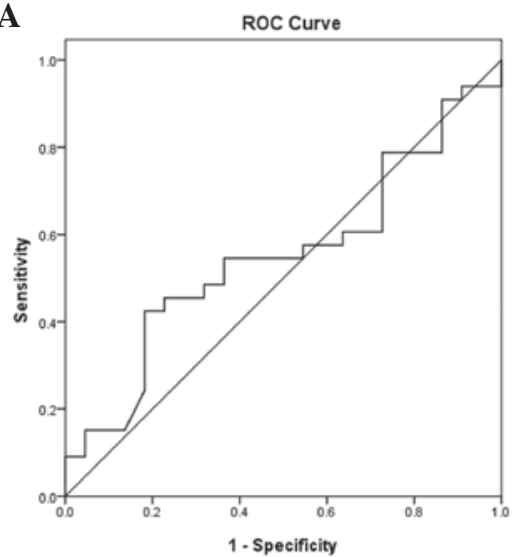

B

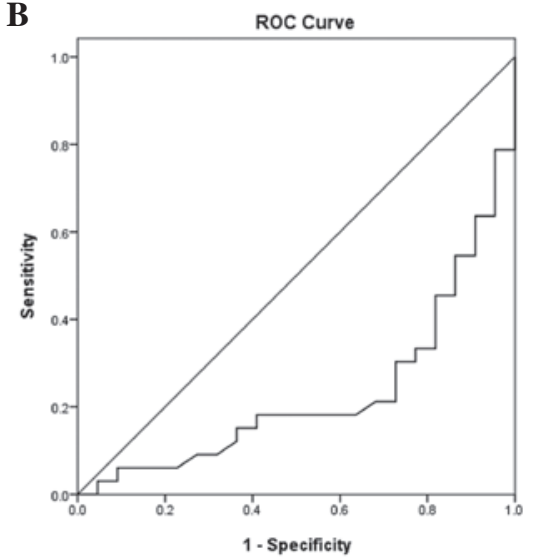

Figure 3. (A) ROC curve of the possibility of (A) serum CA125 and (B) serum HE4 for optimal debulking. HE4, human epididymis protein 4.

ovarian cancer. However, few HE4 promoters are active in ovarian surface epithelial (OSE) cells, indicating that the increase in HE4 levels observed in ovarian cancer does not appear in normal ovarian epithelia culture. Moreover, HE4 is not expressed in the normal ovaries, early and late corpus luteum or fallopian tubes. Consequently, the level of serum HE4 may be used as marker for the diagnosis of ovarian cancer. The results of the present study are consistent with those of Moore et al (13) who detected the levels of serum HE4 in epithelial ovarian cancer (129 cases) and benign ovarian tumor patients ( 352 cases) and observed that HE4 was significantly increased in the epithelial ovarian cancer patients. The present study also was consistent with Köbel et al's results (9). Kirchoff et al (6) observed that HE4 was expressed mainly in the distal epithelial cells of the epididymis and epithelial cells of the vas deferens. To further study the correlation between HE4 and ovarian cancer, Wang (14) et al studied the expression of HE4 in various ovarian tissues and revealed that HE4 was highly expressed in cancer tissue but not in normal ovarian tissue and pericancerous tissues. Another study showed that the HE4 secreted by ovarian cancer is a secreted protein resulting from $\mathrm{N}$-glycosylation. Its molecular weight is less than CA125, so HE4 is more likely to be secreted into the blood than CA125 (15) and HE4 may be more effective than CA125 in early diagnosis. The present data also showed that the diagnostic value of HE4 was superior to that of CA125 in stage I-II patients. Montagnana et al (16) studied 46 ovarian cancer patients, 40 benign disease patients and a healthy control group and observed that the release of HE4 occurred earlier than CA125. The levels of HE4 had significantly increased in early ovarian cancer, while the levels of $40-50 \%$ CA125 did not increase. The present study also observed that the level of serum HE4 was the highest in serous carcinoma patients and the difference compared with other types of ovarian cancer was statistically significant $(\mathrm{P}<0.01)$. Drapkin et al (15) investigated the expression of HE4 in various types of ovarian cancer organization using an immunohistochemical method and observed that HE4 was expressed in $50 \%$ of ovarian clear cell carcinomas, $93 \%$ of ovarian serous ovarian cancer and $100 \%$ of endometrioid carcinomas of the ovary. However, it 
was not expressed in mucinous ovarian cancer and normal ovarian tissues. Therefore, the diagnostic value of HE4 may vary with the histopathological type. The present study also showed that the level of serum HE4 was highest in serous adenocarcinoma and clear cell carcinoma, compared with the other types of ovarian cancer, although no statistically significant difference was observed among mucinous adenocarcinoma, endometrial adenocarcinoma and undifferentiated carcinoma. Nolen et al (17) studied 65 tumor markers for the diagnosis of ovarian cancer and identified 34 significant markers. The diagnostic value of HE4 was the highest, followed by CYFRA 21-1, CA125 and CA-19-9. The sensitivity of the diagnosis of early ovarian cancer was improved from 74.2 to $91.7 \%$ by the combined detection of HE4 and CA125. It has been suggested that this combined detection is superior to the single detection of CA125 (18). Although the sensitivity of the joint detection of HE4 and CA125 is superior compared with the single detection of $\mathrm{HE} 4$, the difference is not significant and the specificity is lower compared with a single HE4 indicator. This may be associated with the false positive rate of the single detection of CA125. The present study showed that the sensitivity and specificity were 65 and $98.7 \%$, respectively, for the combined detection of HE4 and CA125. This result was compared with HE4 used alone and it was observed that the sensitivity had decreased but the specificity was increased. When combining CA125 with HE4, if CA125 and HE4 were positive the combination was considered positive. The sensitivity and specificity of the combination $(77.5 \%$ and $88.75 \%$, respectively) were decreased compared with HE4 alone. Therefore, the present study suggests that the combined detection of HE4 and CA125 contributes to the differential diagnosis of benign or malignant pelvic masses, but is not superior to the single detection of HE4 for the early diagnosis of ovarian cancer.

Certain studies have investigated whether HE4 may be used as a marker to monitor disease progress and predict prognoses. The study of Xu et al (19) showed that the expression level of serum HE4 was significantly higher in a preoperative ovarian cancer group compared with healthy, benign ovarian epithelial tumor and borderline ovarian tumor groups and the differences were statistically significant $(\mathrm{P}<0.05)$. However, the serum HE4 expression level in postoperative ovarian cancer patients was significantly lower than the preoperative level, indicating that the level of serum HE4 may have play a role in the evaluation of surgical treatment. Although surgery is the major treatment option in ovarian cancer, its effect is often compromised by early and insidious extra-pelvic metastases, such as subphrenic and mesenteric root lesions, particularly in the superior abdomen region. The early diagnosis and accurate preoperative assessment of metastasis in ovarian carcinoma patients is critical for achieving optimal debulking and improving the five-year survival rate. The present study provides evidence that preoperative serous HE4 testing in the ovarian cancer patients may be regarded as an index for estimating the possibility of optimal cytoreductive surgery. The demarcation criterion was $600 \mathrm{pmol} / \mathrm{l}$, where a value $>600 \mathrm{~mol} / 1$ indicates a lower possibility of optimal debulking by cytoreductive surgery. HE4 predicted that the sensitivity of incomplete cytoreductive surgery was $77 \%$ and the specificity was $32 \%$. The present data also showed significant differences between the Kaplan-Meier survival curves of HE4-positive and negative patients $(\mathrm{P}=0.036$, log-rank test). This suggested that the prognosis of ovarian cancer patients with higher concentrations of serum HE4 was worse than those without serum HE4. The Cox proportional hazards regression model was also used to analyze whether HE4 could be used as an independent prognostic factor, with the following factors: HE4-positive and negative, age, pathological type (epithelial and non-epithelial), stage (I-II and III-IV), distant organ transfer, ascites and postoperative residual focal factors. The results showed that the independent prognostic factors affecting the survival of ovarian cancer patients were clinical stage, distant organ metastasis and postoperative residual foci, while HE4, pathological type, lymph node metastasis and omentum majus metastasis were not independent prognostic factors affecting survival. This may be due to the small sample size and short follow-up period.

\section{Acknowledgements}

The present study was supported by a grant from the Provincial Research Project Funding of Guangxi, China (Nos. 2010GXNSFD013053 and Z2011217).

\section{References}

1. Shaaban A and Rezvani M: Ovarian cancer: detection and radiologic staging. Clin Obstet Gynecol 52: 73-93, 2009.

2. Chen WQ, Zhang SW and Zou XN: Cancer incidence and mortality in China, 2006. Chin J Cancer Res 23: 3-9, 2011 (In Chinese).

3. Nolen BM and Lokshin AE: Protein biomarkers of ovarian cancer: the forest and the trees. Future Oncol 8: 55-71, 2012.

4. Li J, Dowdy S, Tipton T, et al: HE4 as a biomarker for ovarian and endometrial cancer management. Expert Rev Mol Diagn 9: 555-566, 2009.

5. Kirchhoff C, Habben I, Ivell R and Krull N: A major human epididymis-specific cDNA encodes a protein with sequence homology to extracellular proteinase inhibitors. Biol Reprod 45: 350-357, 1991.

6. Kirchhoff C: Molecular characterization of epididymal proteins. Rev Reprod 3: 86-95, 1998.

7. Galgano MT, Hampton GM and Frierson HF Jr: Comprehensive analysis of HE4 expression in normal and malignant human tissues. Mod Pathol 19: 847-853, 2006.

8. Moore RG, Brown AK, Miller MC, Skates S, Allard WJ, Verch T, Steinhoff M, Messerlian G, DiSilvestro P, Granai CO and Bast RC Jr: The use of multiple novel tumor biomarkers for the detection of ovarian carcinoma in patients with a pelvic mass. Gynecol Oncol 108: 402-408, 2008.

9. Köbel M, Kalloger SE, Boyd N, McKinney S, Mehl E, Palmer C, Leung S, Bowen NJ, Ionescu DN, Rajput A, Prentice LM, Miller D, Santos J, Swenerton K, Gilks CB and Huntsman D: Ovarian carcinoma subtypes are different diseases: implications for biomarker studies. PLoS Med 5: e232, 2008.

10. Deraco M, Baratti D, Laterza B, et al: Advanced cytoreduction as surgical standard of care and hyperthermic intraperitoneal chemotherapy as promising treatment in epithelial ovarian cancer. Eur J Surg Oncol 37: 4-9, 2011.

11. Chua TC, Liauw W, Robertson G and Morris DL: Second-line treatment of first relapse recurrent ovarian cancer. Aust $\mathrm{N}$ Z J Obstet Gynaecol 50: 465-471, 2010.

12. Berry NB, Cho YM, Harrington MA, Williams SD, Foley J and Nephew KP: Transcriptional targeting in ovarian cancer cells using the human epididymis protein 4 promoter. Gynecol Oncol 92: 896-904, 2004. 
13. Moore RG, McMeekin DS, Brown AK, DiSilvestro P, Miller MC, Allard WJ, Gajewski W, Kurman R, Bast RC Jr and Skates SJ: A noval multiple marker bioassay utiliazing HE4 and CA125 for the prediction of ovarian cancer in patients with a pelvic mass. Gynecol Oncol 112: 40-46, 2009.

14. Wang K, Gan L, Jeffery E, Gayle M, Gown AM, Skelly M, Nelson PS, Ng WV, Schummer M, Hood L and Mulligan J: Monitoring gene expression profile changes in ovarian carcinomas using cDNA microarray. Gene 229: 101-108, 1999.

15. Drapkin R, von Horsten HH, Lin Y, Mok SC, Crum CP, Welch WR and Hecht JL: Human epididymis protein 4 (HE4) is a secreted glycoprotein that is overexpressed by serous andendometrioid ovarian carcinomas. Cancer Res 65: 2162-2169, 2005.

16. Montagnana M, Lippi G, Ruzzenente O, Bresciani V, Danese E, Scevarolli S, Salvagno GL, Giudici S, Franchi M and Guidi GC: The utility of serum human epididymis protein 4 (HE4) in patients with a pelvic mass. J Clin Lab Anal 23: 331-335, 2009 .
17. Nolen B, Velikokhatnaya L, Marrangoni A, De Geest K, Lomakin A, Bast RC Jr and Lokshin A: Serum biomarker panels for the discrimination of benign from malignant cases in patients with an adnexal mass. Gynecol Oncol 117: 440-445, 2010.

18. Andersen MR, Goff BA, Lowe KA, Scholler N, Bergan L, Drescher CW, Paley P and Urban N: Use of a symptom index, CA125, and HE4 to predict ovarian cancer. Gynecol Oncol 116: 378-383, 2010.

19. Xu CL, Yang YH and Wang HL: The value of serum human epididymis protein 4 epithelial in the diagnosis of ovarian cancer. Chinese Journal of Gynecology and Obstetrics 26: 684-686, 2010. 